\title{
Application of Group Hunting Search Optimized Cascade PD-Fractional Order PID Controller in Interconnected Thermal Power System
}

\author{
Jyoti Ranjan Nayak* and Binod Shaw \\ Department of Electrical Engineering, National Institute of Technology, Raipur, India
}

Received January 4, 2018; Accepted March 15, 2018; Published April 23, 2018

\begin{abstract}
This paper is an endeavor to enhance the performance of the Automatic Generation Control (AGC) by adopting cascade PD-FOPID (Proportional Derivative - Fractional Order PID) controller in a two-area mutually connected thermal power plant with Generation Rate Constraint (GRC). The performance of the cascade PD-FOPID controller is validated by contrasting PID and FOPID controllers implemented in each area as AGC. The basic goal of the design of these controllers is to lessen the area control error (ACE) of corresponding area by conceding the frequency and tie-line power deviation. Group Hunting Search (GHS) algorithm is adopted to explore the gain parameters of the controllers to lessen the objective function (ITAE). A small step load transition of 0.01 p.u. is enforced in area-1 to investigate the controller performance. Cascade PD-FOPID controller optimized by GHS algorithm performs precisely better than PID and FOPID controller in the proposed system.
\end{abstract}

Keywords: Automatic Generation Control (AGC); Proportional-Integral-Derivative controller (PID); Fractional Order PID (FOPID); Group Hunting Search (GHS); Cascade PD-FOPID controller

\section{Introduction}

In the power system, the basic objective is to counterbalance the generated power and demand power comprising power loss. Interconnected power system is a significant advent to utilize the generating units and transmission lines intelligently to counterbalance the power. The rotating mass of the generators are the primary controllers to regulate the small deviations of frequency and power. Due to the huge deviation of load, the diversity of frequency and tie-line power extends over the different mutually connected areas. The secondary controller Automatic Generation Control (AGC) is a significant approach to handle the huge deviations of frequency and power. The capability to attain the stability is enhanced due to the fast response of the secondary controller $[1,2]$. The fast response of AGC enhances the capability of the system to handle continuous deviation of load. The fundamental objectives of AGC are

i. To contribute reliable, stable, economic and quality power.

ii. To set the system frequency to the nominal frequency.

iii. To lessen the undershoot $\left(\mathrm{U}_{\mathrm{sh}}\right)$, overshoot $\left(\mathrm{O}_{\mathrm{sh}}\right)$ and settling time $\left(\mathrm{T}_{\mathrm{s}}\right)$ of the frequency and tie-line power deviation. 
Many concepts to enhance the ability of AGC have been proposed by many authors from last few decades. Conventional PID controller is validated over I and PI controllers optimized by Imperialist Competitive Algorithm (ICA) as illustrated in [3, 4]. The cascade combination of PI and PD controllers is adopted as inner and outer controller loop in multi-area power system. The cascade PI-PD controller is validated as a better controller over conventional PID controller and the parameters of the controller are tuned by Flower Pollination Algorithm (FPA) to enhance the performance of the controller in [5]. The degree of freedom (DOF) of the PID controller is increased in $[6,7]$ entitled as 2DOF PID controller to enhance the performance of the AGC in the multiarea power system optimized by Cuckoo Search Algorithm (CSA) and Teaching Learning Based Optimization (TLBO) algorithms respectively. The superiority of FuzzyPID controller optimized by various algorithms and hybrid algorithms over PID as AGC is validated in [8-12]. Xue and Chen [13] have portrayed a brief comparison between four different types of fractional order controller. Fractional order PID controller (FOPID), Tilted Integral Derivative controller (TID), and fuzzy-FOPID controller optimized by different algorithms are adopted as AGC in [14-24]. Application of some superior algorithms in the power system is beautifully expressed in [25-28].

The basic purpose of this paper is to design AGC for two-area power system. Each area subsists of a thermal power unit with Generation Rate Constraint (GRC) with saturation limit of \pm 0.05 . PID, FOPID, and PD-FOPID controllers are adopted as the controller in the system to minimize the objective function by concerning frequency and power deviations. The design variables (controller gains) enormously influence the system performance. Group Hunting Search (GHS) technique is adopted to minimize the error of this single objective constraint problem by hunting the appropriate pair of controller gains.

\section{System Investigated}

The proposed system is a two-area coupled together by tie-line. Thermal power plants of same characteristics with GRC reside in each area of the interconnected system. The model of the system is portrayed in Fig. 1. Normally hydro and thermal power plants have a saturation limit of change of generated power. The generation power can swift at a particular maximum rate. Generation rate is considered for the proposed system with 5\% $( \pm 0.05)$ of saturation limit. The transfer function parameters are portrayed in appendix 1 . A small load swift of 5\% (0.05) in area-1 is implemented to analyze the transient response of the system. This load change in area-1 propagates error in both the areas entitled as Area Control Errors $\left(\mathrm{ACE}_{1}\right.$ and $\left.\mathrm{ACE}_{2}\right)$. ACEs concerning deviations of frequency and tie-line power have to be minimized and may be defined as equations (1) and (2).

$$
\begin{aligned}
& A C E_{1}=B_{1} \Delta f_{1}+\Delta P_{t i e} \\
& A C E_{2}=B_{2} \Delta f_{2}+\Delta P_{t i e}
\end{aligned}
$$

Where $B_{1}$ and $B_{2}$ are the bias factors. The deviations of frequency with respect to nominal values in the area- 1 and area- 2 are $\Delta \mathrm{f}_{1}$ and $\Delta \mathrm{f}_{2}$, respectively. The deviation of power in tie-line is $\Delta \mathrm{P}_{\text {tie }}$ and is characterized in equation (3). 


$$
\Delta P_{\text {tie }}=\frac{2 \pi T_{12}}{s}\left(\Delta f_{1}-\Delta f_{2}\right)
$$

PID, FOPID and PDFOPID controllers are executed in both the areas individually to examine the controller potential to enhance the system performance. Intelligent PDFOPID controller is observed as a superior controller over PID and FOPID controllers. ITAE (Integral Time Absolute Error) holds fine capability to handle long period transients of the signal than ISE, IAE, and ITSE indices as described in [23]. The sensitivity of deviations increases with respect to time, i.e., small deviations from the nominal value after a long period are higher sensitive than large deviations earlier. ITAE is adopted as objective function by concerning errors $\left(\Delta \mathrm{f}_{1}, \Delta \mathrm{f}_{2}\right.$, and $\left.\Delta \mathrm{P}_{\text {tie }}\right)$ and time as described in equation (4).

$$
I T A E=\int_{0}^{T} t\left(\Delta f_{1}+\Delta f_{2}+\Delta P_{t i e}\right)
$$

Subject to

$$
0.001 \leq K_{i} \leq 2 i=1,2, \Lambda, n
$$

Where $\mathrm{n}$ is the designed variable.

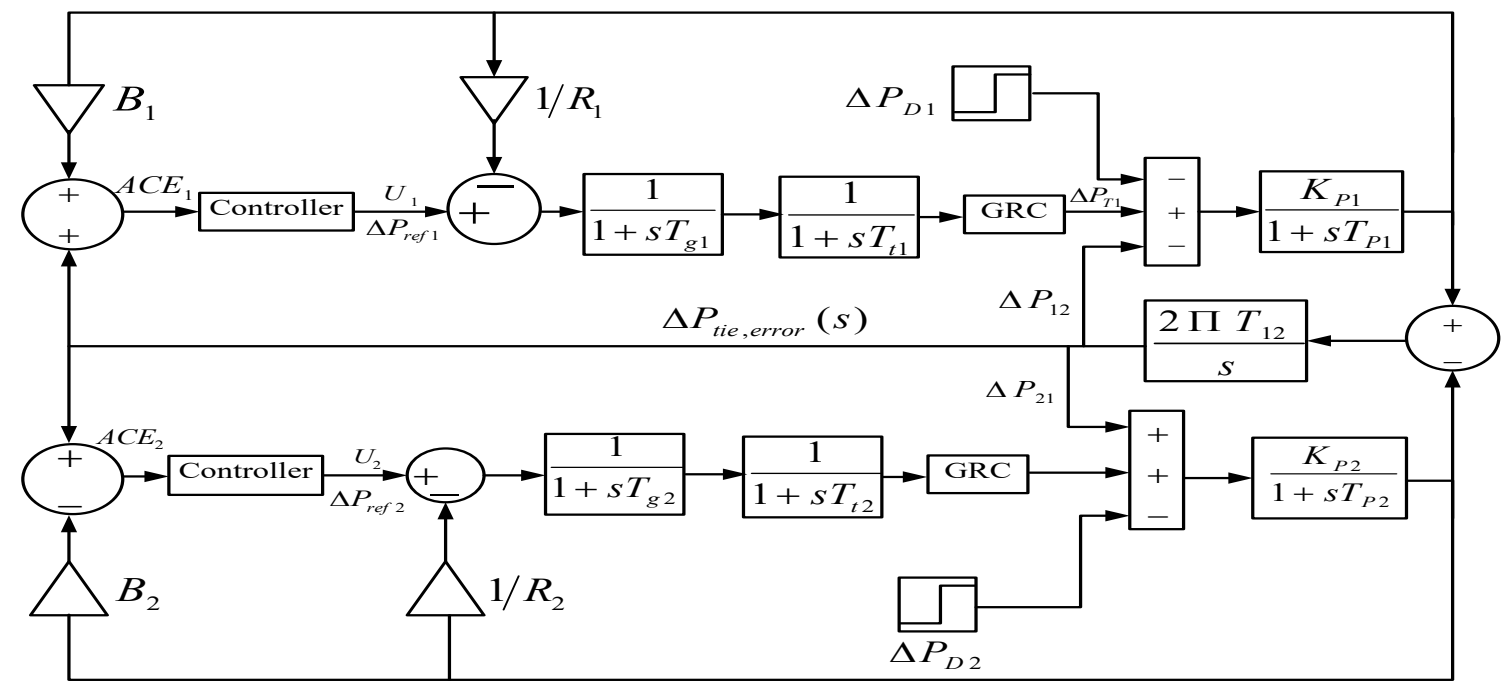

Figure 1. Power system model [24]

\section{Controller Structure}

The performance of the system mostly relies upon the controller design. Picking up the appropriate pair of gain parameters of controllers is also very significant factor.

\section{FOPID Controller}

Fractional order PID controller is a novel approach recommended from the fractional calculus. The orders of the integration and differentiation $(\lambda$ and $\mu)$ are fractional values. $\lambda$ and $\mu$ values may not be integer. The transfer function of the FOPID controller is characterized in equation (5).

$$
G_{C}(s)=K_{P}+\frac{K_{I}}{s^{\lambda}}+s^{\mu} K_{D}
$$


Due to fractional order, it has supremacy control over PID controller to maintain stability of the system. PID and FOPID controller structures are portrayed in Fig. 2(a) and 2(b) respectively.

\section{Cascade PD-FOPID controller}

The purposed controller comprises two loops (inner and outer) arranged in such an aspect that the output of one loop is the input for other loop as portrayed in Fig. 3 [5]. The FOPID controller is adopted as the inner measure which enhances the potency to control the supply disruption that may influence the outer process. The PD controller is adopted as the outer measure to regulate the output quality of the process. This controller has a vital advantage of eradication of noise which make the other parts of the system isolate from the noise.

\section{Outer loop}

This loop is characterized by concerning process output $\mathrm{Y}(\mathrm{s})$, process of outer $\mathrm{G}_{1}(\mathrm{~s})$ and load distortion $\mathrm{d}_{1}(\mathrm{~s})$ as

$$
Y(s)=G_{1}(s) U_{1}(s)+d_{1}(s)
$$

Where $U_{1}(s)$ is the input to the process of outer which is equal to output of the inner loop. Outer loop is adopted to control the error associated with reference $\mathrm{R}(\mathrm{s})$ or to track the reference.

\section{Inner loop} $\mathrm{G}_{2}(\mathrm{~s})$ as

The inner loop is characterized in equation (7) by concerning process of inner

$$
y_{2}(s)=G_{2}(s) U_{2}(s)
$$

Where output of the inner loop fed as input to the outer loop $\mathrm{y}_{2}(\mathrm{~s})=\mathrm{U}_{1}(\mathrm{~s})$.

The prime goal of the inner loop is to comprise the disturbances occurred inside the inner loop itself. The response of the cascade controller depends on fastness of inner controller. The overall transfer function of the cascade controller is characterized in equation (8).

$$
\begin{aligned}
Y(s)=\left[\frac{G_{1}(s) G_{2}(s) C_{1}(s) C_{2}(s)}{1+G_{2}(s) C_{2}(s)+G_{1}(s) G_{2}(s) C_{1}(s) C_{2}(s)}\right] R(s) \\
-\left[\frac{G_{1}(s)}{1+G_{2}(s) C_{2}(s)+G_{1}(s) G_{2}(s) C_{1}(s) C_{2}(s)}\right] d_{1}(s)
\end{aligned}
$$

In this paper, PD controller is adopted as outer loop controller and FOPID controller is adopted as inner loop.

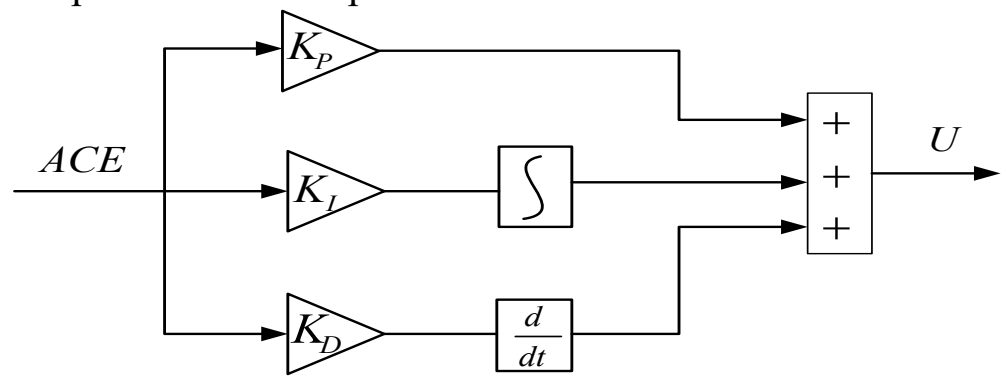

Figure 2(a). PID controller structure 


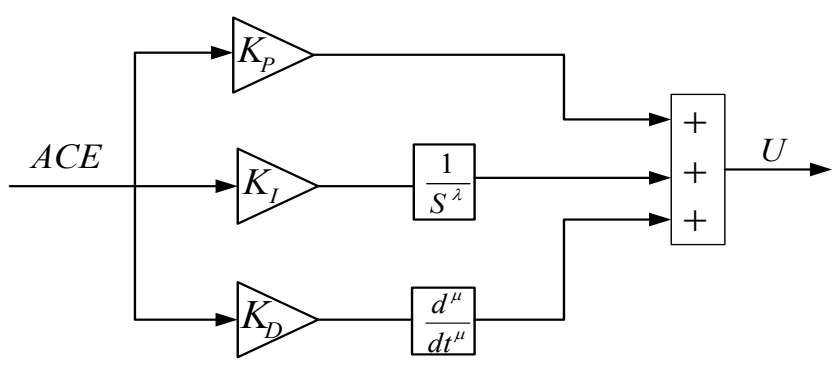

Figure 2(b). Fractional order PID controller structure

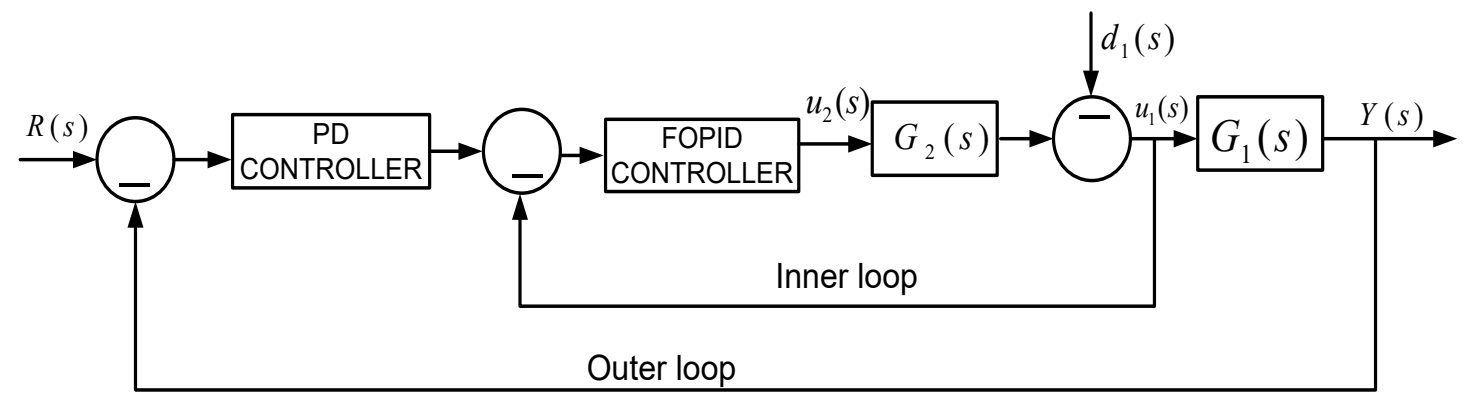

Figure 3. Cascade PD-FOPID controller structure [5]

\section{Group Hunting Search (GHS) Algorithm}

Optimization techniques play an influential aspect to enhance the performance of the controller by searching relevant pair of gain parameters of the controller. In this paper, GHS algorithm is adopted to tune the parameters of PID, FOPID, and PD-FOPID controllers individually to validate the performance of PD-FOPID controller. The basic purpose of optimization is to lessen ITAE by hunting the parameters of controllers within the specified limit as defined in equation (4).

The relation between predator (group hunters i.e., Lions, wolves etc) and prey is beautifully expressed as optimization technique by r. Oftadeh et.al. [22]. GHS algorithm is derived from the strategy of hunting a prey by concerning the group hunting technique. Unity of group members adopts an approach to trap the prey by circumscribing it. The member of the group near to the prey is adopted as the leader and all other members follow the leader to move towards the prey (optimum solution). If any of the group members amends by a better position compared to the recent leader then it becomes the leader in the next generation. The hunter in each generation follows the leader by concerning maximum moments towards the leader (MML). MML affects the technique to counterbalance exploration and exploitation. The strides of the GHS are as

1. Initialize the group of hunters of size $X_{[\mathrm{NP} \times \mathrm{D}]}$ within the limit 0.001 to 2 .

2. The best fitted hunters among the group is adopted as leader.

3. The hunter's positions are refurbished towards the leader. The mathematical expression is defined in equation (9).

$$
\begin{aligned}
& X_{i}^{k+1}=X_{i}^{k}+\operatorname{rand} \times M M L \times\left(X_{i}^{L}-X_{i}^{k}\right) \\
& M M L=0.6-\left(\text { it } \times\left(\frac{0.6}{\text { iter } \max }\right)\right)
\end{aligned}
$$


Where 'it' is the current iteration, itermax is the maximum iterations and $X_{i}^{L}$ is the position of leader.

4. The position of hunters are corrected by concerning Hunter's Group Consideration Rate (HGCR) and distance radius $\left(\mathrm{R}_{\mathrm{a}}\right)$ are represented in equation (10).

$$
\begin{aligned}
& X_{i}^{k+1}= \begin{cases}X_{i}^{k+1} \in\left\{X_{i}^{1}, X_{i}^{2}, \Lambda, X_{i}^{H G S}\right\} \text { with probability } H G C R \\
X_{i}^{k+1} \pm R_{a} \text { with probability }(1-H G C R)\end{cases} \\
& R a(i t)=R a_{\text {min }}\left(\max \left(X_{i}\right)-\min \left(X_{i}\right)\right) \exp \left(\frac{\ln \left(\frac{R a_{\text {min }}}{R a_{\max }}\right) \times i t}{\text { iter max }}\right)
\end{aligned}
$$

$\mathrm{Ra}$ is an exponential decay function and may be defined as in equation (11).

5. Identify the group to avoid the algorithm to be trapped into local optima. It may be characterized in equation (12).

$$
X_{i}^{k+1}=X_{i}^{L} \pm \operatorname{rand}\left(\max \left(X_{i}\right)-\min \left(X_{i}\right)\right) \times \alpha \exp (-\beta \times E N)
$$

Where EN is the numbers of epochs. EN is estimated by matching the difference of leader and worst hunter with a small value.

6. Repeat steps 3 to 5 up to termination criteria satisfied. In this problem, maximum iteration (100) is treated as termination criteria

In appendix. 2 all the specifications of GHS are portrayed.

\section{Results and Discussion}

Cascade PD-FOPID, FOPID and PID controllers are implemented in both areas individually. GHS algorithm is executed with 60 numbers of hunters for 100 iterations to

\begin{tabular}{|c|c|c|c|}
\hline Controllers & \multicolumn{3}{|c|}{ Gains of different Controllers } \\
\hline & & rea1 & Area2 \\
\hline \multirow{7}{*}{ PD-FOPID } & $K_{1}$ & 2.0000 & 2.0000 \\
\hline & $\mathbf{K}_{2}$ & 0.2106 & 0.5617 \\
\hline & $K_{3}$ & 0.0010 & 1.0715 \\
\hline & $\mathbf{K}_{4}$ & 0.1481 & 0.4265 \\
\hline & $\mathbf{K}_{5}$ & 1.5467 & 0.0010 \\
\hline & $\mu$ & 0.4355 & 0.5003 \\
\hline & $\lambda$ & 0.7656 & 0.3372 \\
\hline \multirow{5}{*}{ FOPID } & $K_{1}$ & 0.5476 & 1.3368 \\
\hline & $\mathbf{K}_{2}$ & 0.8072 & 1.0391 \\
\hline & $\mathbf{K}_{3}$ & 1.5488 & 0.5526 \\
\hline & $\mu$ & 0.9954 & 0.6808 \\
\hline & $\lambda$ & 0.8323 & 1.1300 \\
\hline \multirow{3}{*}{ PID } & $K_{1}$ & 0.3353 & 0.3086 \\
\hline & $\mathbf{K}_{2}$ & 1.2274 & 0.5837 \\
\hline & $\mathbf{K}_{3}$ & 0.2072 & 1.2178 \\
\hline
\end{tabular}
tune the controller parameters by concerning ITAE as an objective function.

Table 1. GHS optimized gain parameters of different controllers 
The numbers of parameters to be tuned by GHS algorithm of PD-FOPID, FOPID, and PID controllers are 14, 10 and 6, respectively, and are tabulated in Table 1. The above parameters are within a specified perimeter of 0.001 to 2 .

The convergence plot of GHS algorithm optimized PID, FOPID, and cascade PDFOPID controllers is portrayed in Fig. 4 to validate the potency of PD-FOPID controller. The performance of GHS algorithm optimized PID controller is validated in Fig. 5 by comparing with [24] by implementing load change of 0.05 p.u in the area-1.The performance parameters (undershoot, overshoot and settling time) of tie-line power deviation of GHS optimized PID controller are relatively better over BFOA, GA, and ZN tuned PID controller.

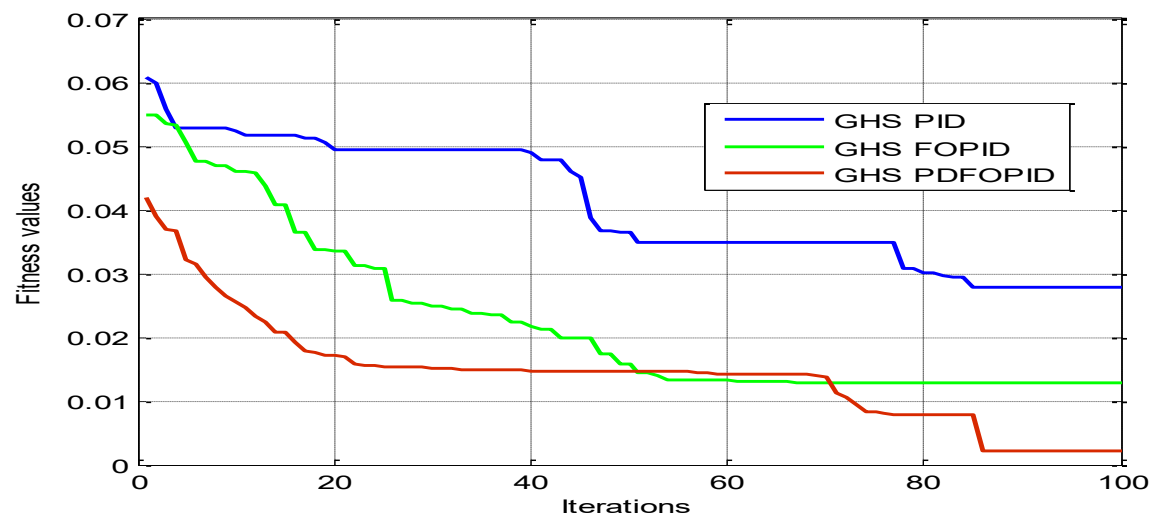

Figure 4. Convergence plot

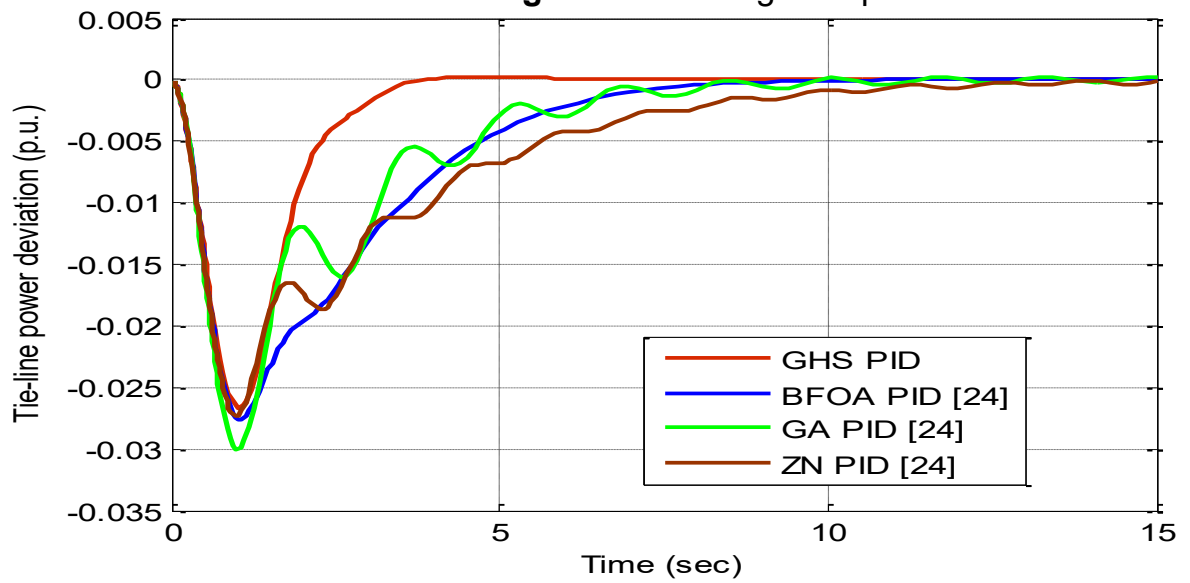

Figure 5. Tie-line power deviation due to $5 \%$ disturbance in area1

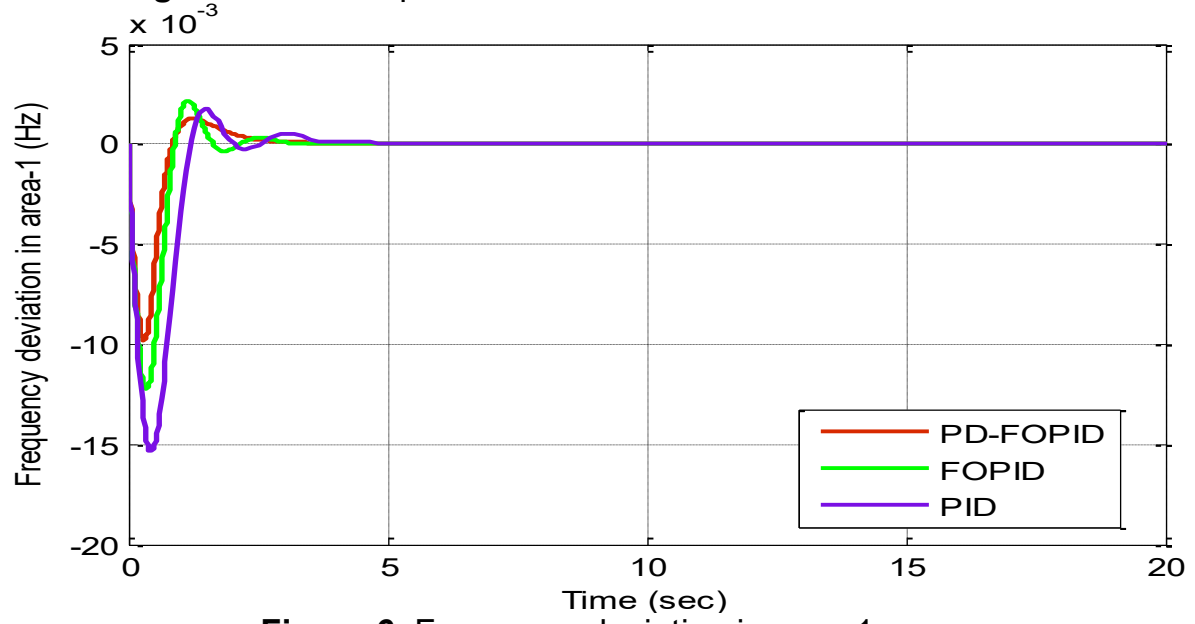

Figure 6. Frequency deviation in area-1 


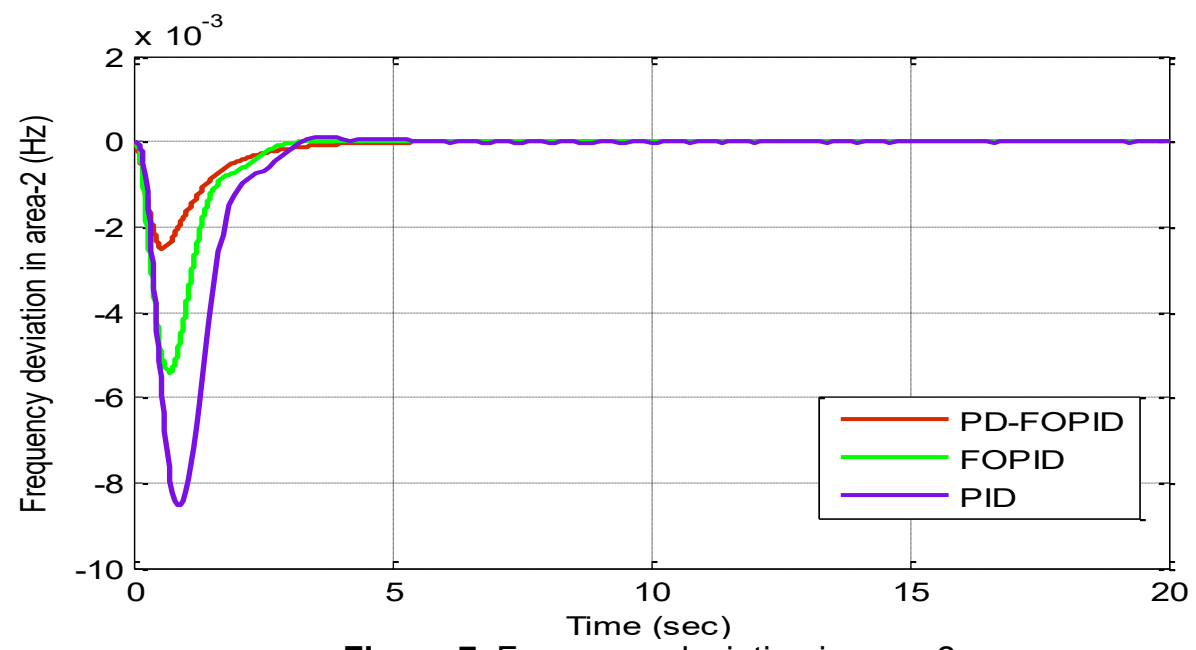

Figure 7. Frequency deviation in area-2

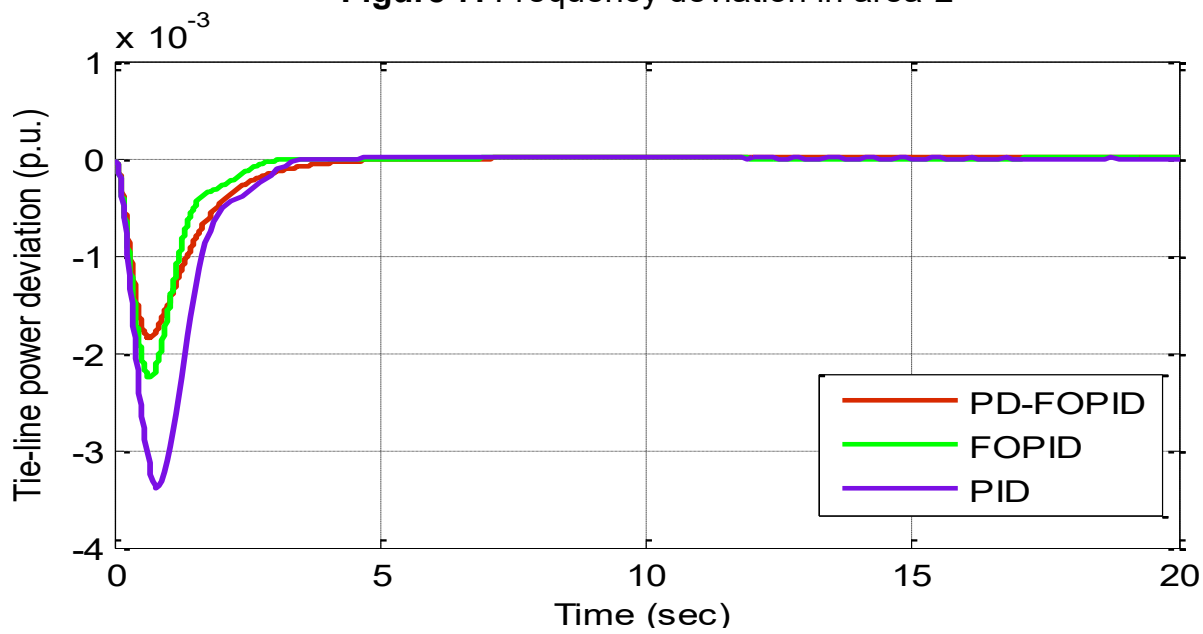

Figure 8. Tie-line power deviation

The frequency deviations of each area and power deviation in tie-line by implementing PD-FOPID, FOPID, and PID controllers optimized by GHS algorithm are portrayed in Fig. 6, Fig. 7 and Fig. 8, respectively.

The frequency deviation in the area- 2 of the system by implementing variable step load change in the area-1 with different controllers optimized by GHS algorithm is illustrated in Fig. 9.

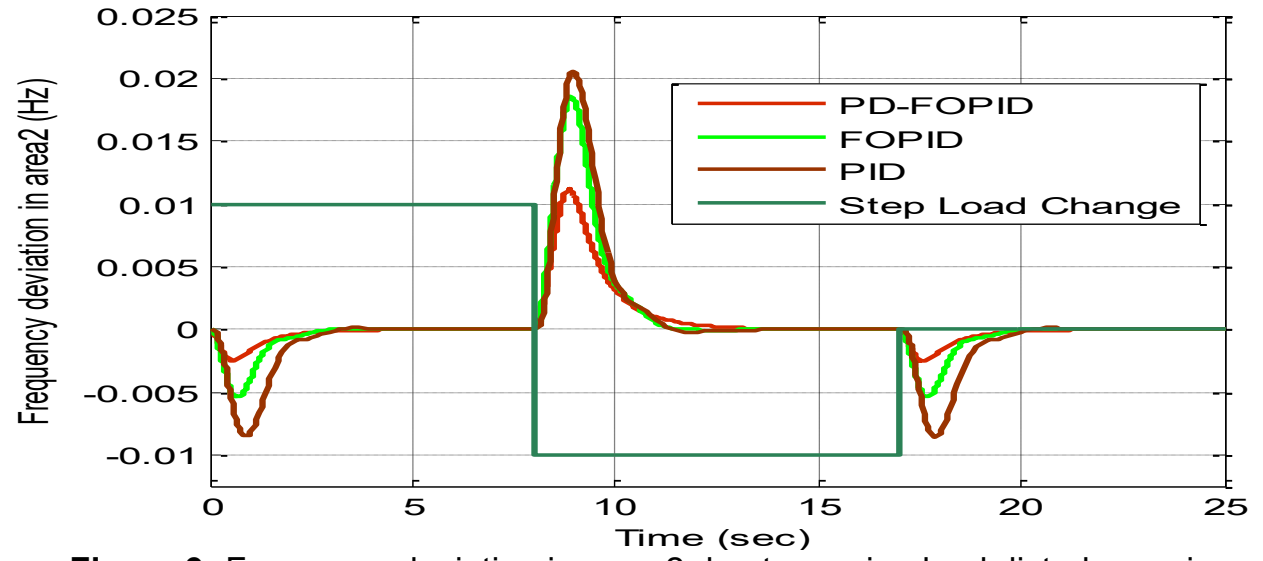

Figure 9. Frequency deviation in area-2 due to varying load disturbance in area-1 
The objective function (ITAE) is adopted to lessen the settling time $\left(\mathrm{T}_{\mathrm{s}}\right)$, peak overshoot $\left(\mathrm{O}_{\mathrm{sh}}\right)$, and peak undershoot $\left(\mathrm{U}_{\mathrm{sh}}\right)$ of the system. The performances of the controllers are discriminated by concerning these parameters and are mentioned below. ITAE value for GHS optimized PD-FOPID, FOPID, and PID controllers are 0.0022, 0.0128 , and 0.0278 , respectively.

Table 2. Peak undershoots $\left(\mathrm{U}_{\mathrm{sh}}\right)$, peak overshoots $\left(\mathrm{O}_{\mathrm{sh}}\right)$ and settling time $\left(\mathrm{T}_{\mathrm{s}}\right)$ of $\Delta \mathrm{f}_{1}, \Delta \mathrm{f}_{2}$ and $\Delta \mathrm{P}_{\text {tie }}$

\begin{tabular}{ccccc}
\hline Controllers & Transient & $\Delta \mathbf{f}_{\mathbf{1}}(\mathbf{H z})$ & $\Delta \mathbf{f}_{\mathbf{2}}(\mathbf{H z})$ & $\Delta \mathbf{P}_{\text {tie }}(\mathbf{p . u}$.) \\
\hline \multirow{3}{*}{ PD-FOPID } & $\mathrm{U}_{\mathrm{sh}}\left(\mathrm{x} 10^{-4}\right)$ & $\mathbf{- 9 8 . 1 5 9 1}$ & $\mathbf{- 2 5 . 1 3 1 7}$ & $\mathbf{- 1 8 . 3 8 2 6}$ \\
& $\mathrm{O}_{\mathrm{sh}}\left(\mathrm{x} 10^{-4}\right)$ & $\mathbf{1 2 . 7 1 6 6}$ & $\mathbf{0}$ & $\mathbf{0}$ \\
& $\mathrm{T}_{\mathrm{s}}$ & $\mathbf{2 . 7 2 1 2}$ & $\mathbf{2 . 2 9 0 1}$ & $\mathbf{2 . 7 6 4 5}$ \\
\hline \multirow{2}{*}{ FOPID } & $\mathrm{U}_{\mathrm{sh}}\left(\mathrm{x} 10^{-4}\right)$ & -122.6897 & -54.0853 & -22.4717 \\
& $\mathrm{O}_{\mathrm{sh}}\left(\mathrm{x} 10^{-4}\right)$ & 21.5698 & 0 & 0 \\
& $\mathrm{~T}_{\mathrm{s}}$ & 2.8856 & 2.5455 & 2.3210 \\
\hline \multirow{2}{*}{ PID } & $\mathrm{U}_{\mathrm{sh}}\left(\mathrm{x} 10^{-4}\right)$ & -153.4037 & -85.2842 & -33.8487 \\
& $\mathrm{O}_{\mathrm{sh}}\left(\mathrm{x} 10^{-4}\right)$ & 17.7239 & 1.2366 & 0 \\
& $\mathrm{~T}_{\mathrm{s}}$ & 3.4721 & 2.9451 & 2.9315 \\
\hline
\end{tabular}

Settling time is evaluated by considering a dimension of $\pm 0.05 \%\left(5 \times 10^{-4}\right)$ of final value. $\mathrm{T}_{\mathrm{s}}, \mathrm{U}_{\mathrm{sh}}$, and $\mathrm{O}_{\mathrm{sh}}$ of the system are minimum with PD-FOPID controller optimized by GHS algorithm as reported in Table 2 .

Cascade PD-FOPID controller optimized by GHS algorithm is validated as the better controller over PID and FOPID controllers.

\section{Conclusion}

The purpose of this paper is to validate the performance of cascade PD-FOPID controller optimized by GHS algorithm as an improved secondary controller of the interconnected thermal power system by concerning GRC. For this purpose, PID, FOPID, and cascade PD-FOPID controllers are applied individually in each area as AGC. All the controllers are optimized by GHS algorithm by conceding the termination criteria as maximum iterations (100). The minimum functional value is attained by cascade PDFOPID controller optimized by GHS algorithm over PID and FOPID controllers. With $1 \%$ load disturbance in the area-1, PD-FOPID controller is validated better over PID and FOPID controllers to enhance the ability to get better control over tie-line power deviation and frequency deviations by considering their settling time, undershoots, and overshoot. The supremacy of PD-FOPID controller is validated over PID and FOPID controllers optimized by GHS algorithm.

Appendix.1 (power system parameters)

$\mathrm{K}_{\mathrm{p} 1}=\mathrm{K}_{\mathrm{p} 2}=120 \mathrm{~Hz} /$ p.u. $\mathrm{MW}, \mathrm{T}_{\mathrm{P} 1}=\mathrm{T}_{\mathrm{P} 2}=20 \mathrm{~s}, \mathrm{~B}_{1}=\mathrm{B}_{2}=0.4249 ; \mathrm{R}_{1}=\mathrm{R}_{2}=2.4 \mathrm{~Hz} /$ p.u. $\mathrm{MW}$; $\mathrm{T}_{\mathrm{g} 1}=\mathrm{T}_{\mathrm{g} 1}=0.08 \mathrm{~s} ; \mathrm{T}_{\mathrm{t} 1}=\mathrm{T}_{\mathrm{t} 1}=0.3 \mathrm{~s}$;

Appendix.2 (Assumptions of algorithms)

$\mathrm{HGCR}=0.3 ; \mathrm{Ra}_{\max }=0.0001 ; \mathrm{Ra}_{\min }=1 \times 10^{-6}$; 


\section{CONFLICTS OF INTEREST}

The authors declare that there is no conflict of interests regarding the publication of this paper.

\section{References}

[1] P. S. Kundur, N.J. Balu, M.G. Lauby, Power system stability and control. Vol. 7. 1994: McGraw-hill New York.

[2] N. Cohn, "Some Aspects of Tie-Line Bias Control on Interconnected Power Systems, ” AIEE Transactions, vol. 75, pp. 1415-1436, 1957.

[3] A. Khodabakhshian, R. Hooshmand, "A new PID controller design for automatic generation control of hydro power systems," Int. J. Electr. Power Energy Syst., vol. 32, no. 5, pp. 375-382, 2010.

[4] H. Shabani, B. Vahidi, M. Ebrahimpour, "A robust PID controller based on imperialist competitive algorithm for load-frequency control of power systems," ISA Trans., vol. 52, no. 1, pp. 88-95, 2013.

[5] P. Dash, L. C. Saikia, N. Sinha, "Flower Pollination Algorithm Optimized PI-PD Cascade Controller in Automatic Generation Control of a Multi-area Power System," Int. J. Electr. Power Energy Syst., vol. 82, pp. 19-28, 2016.

[6] P. Dash, L. C. Saikia, N. Sinha, "Comparison of performances of several Cuckoo search algorithm based 2DOF controllers in AGC of multi-area thermal system," Int. J. Electr. Power Energy Syst., vol. 55, pp. 429-436, 2014.

[7] R. K. Sahu, S. Panda, U. K. Rout, D. K. Sahoo, "Teaching learning based optimization algorithm for automatic generation control of power system using 2DOF PID controller," Int. J. Electr. Power Energy Syst., vol. 77, pp. 287-301, 2016.

[8] S. P. Ghoshal, "Optimizations of PID gains by particle swarm optimizations in fuzzy based automatic generation control," Electr. Power Syst. Res., vol. 72, no. 3, pp. 203-212, 2004.

[9] B.K. Sahu, T.K. Pati, J.R. Nayak, S. Panda, S.K. Kar, "A novel hybrid LUS-TLBO optimized fuzzy-PID controller for load frequency control of multi-source power system,” Int. J. Electr. Power Energy Syst., vol. 74, pp. 58-69, 2016.

[10]B.K. Sahu, S. Pati, P.K. Mohanty, S. Panda, "Teaching-learning based optimization algorithm based fuzzy-PID controller for automatic generation control of multi-area power system," Appl. Soft Comput. J., vol. 27, pp. 240-249, 2015.

[11]J. R. Nayak, B. Shaw, "Load frequency control of hydro-thermal power system using fuzzy PID controller optimized by hybrid DECPSO algorithm," IJPAM, vol. 114, no. I, pp. 3-6, 2017.

[12]R.K. Sahu, S. Panda, G.T. Chandra Sekhar, "A novel hybrid PSO-PS optimized fuzzy PI controller for AGC in multi area interconnected power systems," Int. J. Electr. Power Energy Syst., vol. 64, pp. 880-893, 2015.

[13]D. Xue, Y.A. Chen, "Comparative Introduction of Four Fractional Order Controllers," in Proceedings of the 4th World Congress on Intelligent Control and Automation, Shanghai, P.R. China, pp. 3228-3235, 10-14 June 2002. DOI: 10.1109/WCICA.2002.1020131 
[14]I. Pan, S. Das, "Fractional Order AGC for Distributed Energy Resources Using Robust Optimization," IEEE Transactions on Smart Grid, vol. 7, no. 5, pp. 21752186, 2016.

[15] V. H. Haji, C. A. Monje, "Fractional order fuzzy-PID control of a combined cycle power plant using Particle Swarm Optimization algorithm with an improved dynamic parameters selection,” Appl. Soft Comput., vol. 58, pp. 256-264, 2017.

[16]A. Sikander, P. Thakur, R. C. Bansal, S. Rajasekar, "A novel technique to design cuckoo search based FOPID controller for AVR in power systems," Comput. Electr. Eng., 2017. DOI: 10.1016/j.compeleceng.2017.07.005

[17]J. Morsali, K. Zare, M.T. Hagh, "Comparative performance evaluation of fractional order controllers in LFC of two-area diverse-unit power system with considering GDB and GRC effects," J. Electr. Syst. Inf. Technol., 2017. DOI: 10.1016/j.jesit.2017.05.002

[18]P.N. Topno, S. Chanana, "Tilt Integral Derivative control for Two-area Load Frequency Control Problem," In: Proc., 2015 2nd International Conference on Recent Advances in Engineering \& Computational Sciences (RAECS), pp. 1-6, 2015. DOI: $10.1109 /$ raecs.2015.7453361

[19] M. Zamani, M. Karimi-Ghartemani, N. Sadati, M. Parniani, "Design of a fractional order PID controller for an AVR using particle swarm optimization," Control Eng. Pract., vol. 17, no. 12, pp. 1380-1387, 2009.

[20]R. Kumar Sahu, S. Panda, A. Biswal, G. T. Chandra Sekhar, "Design and analysis of tilt integral derivative controller with filter for load frequency control of multi-area interconnected power systems," ISA Trans., vol. 61, pp. 251-264, 2016.

[21]H. Senberber, A. Bagis, "Fractional PID controller design for fractional order systems using ABC algorithm," In: Proc., 2017 Electronics, pp. 1-7, 2017. DOI: 10.1109/electronics.2017.7995218

[22]R. Oftadeh, M.J. Mahjoob, M. Shariatpanahi, "A novel meta-heuristic optimization algorithm inspired by group hunting of animals: Hunting search," Comput. Math. with Appl., vol. 60, no. 7, pp. 2087-2098, 2010.

[23]Y. Oysal, "A comparative study of adaptive load frequency controller designs in a power system with dynamic neural network models," Energy Convers. Manag., vol. 46, no. 15-16, pp. 2656-2668, 2005.

[24]E. S. Ali, S. M. Abd-Elazim, "Electrical Power and Energy Systems BFOA based design of PID controller for two area Load Frequency Control with nonlinearities," Int. J. Electr. Power Energy Syst., vol. 51, pp. 224-231, 2013.

[25]B. Shaw, A. Banerjee, V. Mukherjee, S. P. Ghoshal, "Solution of Optimal Power Flow by an Opposition-Based Gravitational Search Algorithm", Intelligent Computing and Applications, vol. 343, pp. 545-557, 2015.

[26]B. Shaw, V. Mukherjee, S. P. Ghoshal, "Solution of reactive power dispatch of power systems by an opposition-based gravitational search algorithm," Int. J. Electr. Power Energy Syst., vol. 55, pp. 29-40, 2014.

[27] J. R. Nayak, B. Shaw, B. K. Sahu, "Application of adaptive-SOS (ASOS) algorithm based interval type-2 fuzzy-PID controller with derivative filter for automatic generation control of an interconnected power system," Int. J. Engineering Science and Technology, 2018. DOI: 10.1016/j.jestch.2018.03.010

[28]J.R. Nayak, B. Shaw, S. Das, B.K. Sahu, "Design of MI fuzzy PID controller optimized by Modified Group Hunting Search algorithm for interconnected power system," Microsyst. Technol., 2018. DOI: 10.1007/s00542-018-3788-3 
Article copyright: (C) 2018 Jyoti Ranjan Nayak and Binod Shaw. This is an open access article distributed under the terms of the Creative Commons Attribution 4.0 International License, which permits unrestricted use and distribution provided the original author and source are credited. 